Journal of Social Sciences 7 (3): 423-427, 2011

ISSN 1549-3652

(C) 2011 Science Publications

\title{
The Influence of Parents in Adolescents' Misbehavior
}

\author{
${ }^{1}$ Habibah Elias and ${ }^{2}$ Nooreen Noordin \\ ${ }^{1}$ Department of Educational Foundations, \\ ${ }^{2}$ Department of Language and Humanities Education, \\ Faculty of Educational Studies, University Putra Malaysia, \\ 43400 UPM Serdang, Selangor, Malaysia
}

\begin{abstract}
Positive relationships within the family, parental support, a consistent and constructive parental discipline style and adult supervision tend to be related negatively to adolescents deviant behaviors and their associations with deviant peers. Poor family relationships were found to be associated with higher levels of delinquent behaviors, possibly due to the fact that parents in those families provided poor role models and engaged in ineffective discipline strategies. Problem statement: A considerable number of secondary school students were involved in delinquent behavior and they are not doing well in school. School authorities with the supervision of education departments and the Ministry of Education have done their best to guide and monitor students' discipline. Yet the problems related to misbehavior still occur in schools. A study was conducted on 113 at risk students to examine whether parental factors could contribute to their misbehavior problems. Approach: Interviews were conducted using open ended questions. Data were analyzed qualitatively using in vivo software to extract categories of parental influence. Results and Conclusion: Findings showed that the adolescents do have problems with their families including lack of parental attention, communication problems and poor relationship between parents. The implications of the findings were discussed.
\end{abstract}

Key words: Adolescents' misbehavior, parental influence, monitoring practices

\section{INTRODUCTION}

In recent years there has been a greater interest in the role of family environment in the development of children behavior including protective and risky behavior. For instance, family interactions, processes and parenting are recognized as significant influences on adolescents development, behavior and substance use (Di-Clemente et al., 2001, Elias et al., 2009a).

Once children enter school, they get involved in activities which are beyond the direct supervision of parents. In such activities there is a need for more active parental monitoring to get information about the child. Monitoring practices can include a variety of information gathering strategies, maybe involving parents' awareness of their child's activities and also their interests outside the home, knowledge of their whereabouts and getting to know their child's friends (Nash et al., 2005).

Monitoring can be associated with elements of parental control like imposing rules and restrictions on children's activities. But if there is good parent-child communication, monitoring can have greater impact than parental surveillance and control on decreasing delinquency (Cernkovich and Giordano, 1987; Hosseini et al., 2010) and improving academic performance (Otto and Atkinson, 1997; Elias et al., 2009b).

Good communication has been shown to be important for monitoring purposes, as more information can be gathered about adolescents' activities from their own willing disclosure than from active surveillance by their parents (Stattin and Kerr, 2000).

Family conflict and poor relationships among family members are found to be associated with higher levels of substance use and association with deviant peers (Ary et al., 1999). A study by Sargent and Dalton (2001) reported that adolescents who faced stronger parental disapproval of smoking were less likely to smoke. When both parents strongly disapproved of smoking, peer smoking was found to be reduced. The researchers concluded that interventions for parents of adolescents would be beneficial if parents self-efficacy for enforcing smoking policy could be improved. This could also bring about adolescents self-efficacy for refusing to smoke to also increase.

Corresponding Author: Habibah Elias, Faculty of Educational Studies, University Putra Malaysia, 43400 UPM Serdang, Selangor, Malaysia Tel: 603-8946 8208 Fax: 603-8943 5386 


\section{J. Social Sci., 7 (3): 423-427, 2011}

In another study it was shown that parental guidance can reduce adolescents risk taking behavior. Adolescents who reported satisfactory relationships with their parents were less likely to get engaged in sexual activity, involved in gangs or use tobacco, alcohol or other drugs (Nelson et al., 1999). When parents can communicate their expectations regarding avoidance of certain risky behaviors, there was a significant positive correlation between parental expectations and adolescents behavior. This shows that when adolescents perceived accurately their parents' expectations, they were more likely to conform by avoiding risky behaviors.

Social Cognitive theory (Bandura, 1985), suggests that behavior of friends and family members influence adolescents behavior by providing reinforcement for the behavior and by modeling the outcomes associated with the behavior. For example, smoking friends can expose a student to the immediate positive outcomes associated with smoking such as cool image or group membership, factors that can draw a young person into trying smoking.

A study conducted in Taiwan (Wu et al., 2007) found that students with a strong family connection were less likely to use substances and to be part of a strong peer group. They were more likely to have high academic expectations and to study hard. Thus in Taiwan it was found that the family was protective against substance use by keeping adolescents occupied with family and school activities.

Given the above background, it is the intention of this study to explore some relevant parental factors which could contribute to adolescents' misbehavior. It is hypothesized that a positive family environment which consists of good parent-child relationships, parental acceptance and parental monitoring would reduce the negative impact of peer influence on adolescents' misbehavior and reduces other social problems.

\section{METERIALS AND METHODS}

In order to get an in depth explanation regarding parental influence in adolescents' misbehavior, a qualitative method was used. Merriam (1998) has emphasized that the qualitative study is the most common form of research employed by researchers to discover and understand a phenomenon from the perspectives and world view of the people involved. The method utilized was the semi-structured in depth interviews with selected respondents. The sample were 113 Form Four students who were identified by school counselors from 25 secondary schools selected through cluster sampling from five different zones in Malaysia.
Table 1: Number of respondents according to Zones

\begin{tabular}{|c|c|c|c|}
\hline \multirow[b]{2}{*}{ Zones } & \multicolumn{3}{|c|}{ No. of respondents } \\
\hline & Male & Female & Total \\
\hline Central & 12 & 5 & 17 \\
\hline East & 13 & 10 & 23 \\
\hline South & 16 & 4 & 20 \\
\hline North & 11 & 13 & 24 \\
\hline East Malaysia & 26 & 3 & 29 \\
\hline Total & 78 & 35 & 113 \\
\hline
\end{tabular}

The study focused on form four students as literature has shown that the adolescent population is at risk of academic failure and other behavioral problems.

Procedure: Data were collected after approval from the Ministry of Education and the States' Education Departments were given. Each respondent signed a consent letter for the interview to be tape recorded. At risk students in this study referred to students with low academic performance and were involved in discipline problems. On average five respondents were interviewed from each school. The distribution of respondents interviewed according to zones is shown in Table 1.

Data collection: Interviews were conducted using open-ended questions. Respondents were asked on parental factors that they perceived to be related to their involvement in misbehavior, their feelings regarding their involvement and their expectations. The average duration for each interview was about 40 minutes. All interviews were transcribed verbatim.

Data analysis: The raw data in the form of transcribed interviews were analyzed using the Nvivo software to extract categories of parental influence. These categories were explored further in the transcribed interviews of all 113 respondents until saturation point, that is, until no new categories were found from the data (Strauss and Corbin, 1990).

Findings: Parental factors related to adolescents' misbehavior can be divided into four categories as follows:

- Parental supervision and monitoring

- Communication problems

- Poor parenting practices

- Family conflicts

Parental supervision and monitoring: The importance of parental supervision in the development of children and adolescents has been established through research. Good supervision by parents generally will have positive 
effects on their children's development. Monitoring practices include a variety of information gathering strategies, generally involving parent's awareness of their children's activities and interests outside the home, knowledge of their whereabouts and acquaintance with their child's friends.

Some of the respondents in the study indicated that their parents are busy and have no time for them. Their activities are not being supervised at all. The following excerpts from the interview indicate their views regarding parental supervision and monitoring:

'My parents don't care about me. If I come back late at night, sometimes I get scolded. They know that I went for illegal racing but they do not take any action. They let me use the motorbike.' (R28)

'My father works outstation. My mother is busy running a business in a restaurant. There is no one at home during the day so I am free to do what I like. At night I go out to smoke and watch people gambling'. (R30)

'My parents are divorced. I am staying with my mother. My mother is busy. She works as a cook in a hotel. My sister is also working. Everyday my mother gives me money to spend. Normally, after school, I will buy lunch and eat with friends as there is no food at home'. (R51)

'My parents are divorced. I am staying with my father and step mother. My father does not care about me, even my basic needs. Whether I stay home or not, it does not matter. I spent a lot of time outside the home and my father does not care about me'. (R52)

Communication problems/poor relationships: Good parent-child communications may have a great impact on decreasing delinquency, reducing substance use and improving academic performance (Otto and Atkinson, 1997). Communication between parents and their children is a very crucial aspect in developing a happy atmosphere in the homes. Nevertheless what is happening in reality is far from reaching the ideal level. The excerpts below reflect the existing relationships between parents and their children:

'My parents are not on talking terms. They always quarrel and they do not understand each other. My father beats my mother and sometimes beats me. I am so worried about my future.' (R13)
'I have problems with my father. I don't even talk to him. My father does not eat together with us. He takes his meals outside. Whenever I go out, I don't tell my father. I always tell lies in order to go out with friends and have fun. Otherwise he will not allow me to go out.' (R27)

'After I was involved in a police case involving drugs, my father does not speak to me. Every time I come home he avoids talking to me.' (R38)

'My parents always quarrel and are not on talking terms. They quarrel over money as my father is working in a factory with weekly pay and very difficult to make ends meet.' (R73)

Poor parenting practices: Good parenting practices will have positive effects on the development of children. Parents must understand the needs of their children at different stages. But if they do not fulfill the needs required by the children it is likely that children will develop problems either in their behavior or in adapting themselves in different situations. The excerpts below reflect some of the problems faced by respondents in this study in relation to parenting practices:

'I feel my mother does not love me. She always scold me when I come home late or whenever I go out. She also scolds me when my friends come to the house.' (R25):

'I was expelled from school but my parents did not encourage me to go back to school. They are not concerned with their children's schooling.' (R31)

'I feel I do not have enough love and attention from my parents' (R61)

'I am not happy with the different ways my mother treat us.' (R69)

'I am not allowed to go out with friends. My mother is very strict.

I am not happy with my family. They have strict rules. But I still go out with friends, drink alcohol and fight to release tensions.' (R80)

'My father used to scold and cane his children'. (R90) 


\section{J. Social Sci., 7 (3): 423-427, 2011}

Family conflicts: Conflicts between family members are common but when they are too frequent it can create a situation which is unhealthy for children's development. For positive development of children, parents need to minimize conflicts between them. The following excerpts reflect the conditions that the respondents have to face in their daily lives:

'My father gambles a lot. When he is short of money, he will ask from my mother and they will quarrel. I cannot concentrate on my studies because I feel the tension and always think of my family problem.' (R10)

'My parents always quarrel even over the children. I have a big family and my father is a labourer while my mother is a shoe seamstress.' (R30)

'My parents are divorced and I stay with my stepmother. I am not on good terms with my father.' (R51)

'My parents always quarrel and not talking to each other. We, the children become the victims and often get scolded. We feel like running away from home.' (R73)

\section{RESULTS AND DISCUSSION}

The above categories of parental factors are undoubtedly related to adolescent's misbehavior. The respondents in the study have experienced some misbehavior and they were caught in school for getting involved in acts which are against the school rules. Other than parental factors adolescents' misbehavior can also be influenced by other variables such as the school factor or their peer group. However as parents the responsibility of bringing up children is still on their shoulders whether or not the children are also under the influence of other external factors.

The findings of this study confirm the literature on parental factors in relation to adolescents' misbehavior. For instance the findings of this study confirms that of Ary et al. (1999) which found that family conflicts and poor relationships among family members are associated with higher levels of substance use and association with deviant peers. The findings of the present study also concurs with that of Prinstein et al. (2001) which found that family dysfunction and other psychosocial stressors seem to function as cumulative risk factors that can make adolescents more vulnerable to the negative influences of peers.
The findings of the study indicate that problem adolescents come from problem homes. Thus in order to help the adolescents, the school needs to plan some intervention programs which involve the parents. The parents need guidance in parenting skills so that they will practice the appropriate methods in handling their children. The adolescents too need some rehabilitation program which will benefit them when they are still in school and also when they leave school to be employed. It becomes the responsibility of the school, society including the non government organizations to look at the problem in a holistic manner and plan some practical programs both for the parents and adolescents. Adolescents are still in the process of learning and while doing so they make many mistakes. It is the responsibility of adults to make the necessary corrections especially their own children.

Schools should also try to build supportive learning environment with a caring atmosphere. There should be a close relationship between teachers and students to facilitate students to seek help when needed. With a more conducive environment, students would appreciate teachers and schools better and will be involved in the learning process and less in anti-social behaviors. The school can also assist the parents of problem children in giving them guidance to improve their understanding of their children. A favorable relationship between parents and the school will bring about positive effects on the problem adolescents especially when they grew up as adults in the future.

\section{CONCLUSION}

The family undoubtedly is the most important unit especially in fostering and monitoring behavioral development among adolescents. Hence parents should spare more attention to the growing needs of their adolescents children, know who their friends are, have more quality time, for adolescents just like young children need to be appreciated and have a sense of belonging. Parent Teacher Associations are very relevant in helping parents get involved in their children's school as well as social activities. Activities involving parents, teachers and students should be conducted from time to time to establish networking between the school and the family which at the same time can tackle the problem of at risk students.

\section{REFERENCES}

Ary, D.V., T.E. Duncan, S.C. Duncan and H. Hops, 1999. Adolescent problem behavior: The influence of parents and peers. Behav. Res. Therapy, 37: 217-230. DOI: 10.1016/S00057967(98)00133-8 
Bandura, A., 1985. Social Foundations of Thought and Action: A Social Cognitive Theory. 1st Edn., Prentice Hall, Englewood Cliffs, NJ:, ISBN-10: 013815614X, pp: 544.

Cernkovich, S.A. and P.C. Giordano, 1987. Family relationships and delinquency. Criminology, 25: 295-319. 9125.1987.tb00799.x DOI: $10.1111 / \mathrm{j} .1745-$

Di-Clemente, R.J. and G.M. Wingood, 2001. Parental monitoring: Association with adolescents' risk behaviors. Pediatrics, 107: 1363-1368. PMID: 11389258

Elias, H., R. Mahyuddin and N. Noordin, 2009a. Understanding the misbehavior of at-risk students: Contributing factors. Int. J. Hum., 7: 133-143. http://psasir.upm.edu.my/7701/

Elias, H., R. Mahyuddin, N. Noordin, M.C. Abdullah and S. Roslan, 2009b. Self-efficacy beliefs of at-risk students in Malaysian secondary schools. Int. J. Learn., $\quad$ 16: 201-209. http://ijl.cgpublisher.com/product/pub.30/prod.2149

Hosseini, M., H. Elias, S.E. Krauss and S. Aishah, 2010. A review study on spiritual intelligence, adolescence and spiritual intelligence and related theories. J. Soc. Sci., 6: 429-438. DOI: 10.3844/jssp.2010.429.438

Merriam, S.B., 1998. Qualitative Research and Case Study Applications in Education. 2nd Edn., JoseyBass Publishers, San Francisco, ISBN: 0787910090, pp: 275.

Nash, S.G., A. McQueen and J.H. Bray, 2005. Pathways to adolescent alcohol use: Family environment, peer influence and parental expectations. J. Adolesc. Health, 37: 19-28. PMID: 15963903
Nelson, B.V., T.H. Patience and D.C. Mcdonald, 1999. Adolescent risk behavior and the influence of parents and education. J. Am. Board Fam. Med., 12:

436-4343.

http://www.medscape.com/viewarticle/437098

Otto, L.B. and M.P. Atkinson, 1997. Parental involvement and adolescent development. J. Adolescent Res., 12: 68-89. DOI: 10.1177/0743554897121005

Prinstein, M.J. J. Boegers and A. Sprito, 2001. Adolescents and their health risk behavior, factors that alter or add to peer influence. J. Pediatric Psychol., 26: 287-298. DOI: 10.1093/jpepsy/26.5.287

Sargent, J.D. and M. Dalton, 2001. Does parental disapproval of smoking prevent adolescents from becoming established smokers? Pediatrics, 108: 1256-1262. DOI: 10.1542/peds.108.6.1256

Stattin, H. and M. Kerr, 2000. Parental monitoring: A reinterpretation. Child Dev., 71: 1072-1085. PMID: 11016567

Strauss, A.C. and J.M. Corbin, 1990. Basics of Qualitative Research. 2nd Edn., Sage Publications, Inc., Thousand Oaks, CA., ISBN-10: 0803959400, pp: 336.

Wu, G.H., M.Y. Chong, A.T. Cheng and T.H. Chen, 2007. Correlates of family, school and peer variables with adolescent substance use in Taiwan. Soc. Sci. Med., 64: 2594-2600. PMID: 17433511 